\title{
Cultivation of Critical Thinking Abilities in English Writing Teaching ${ }^{*}$
}

\author{
Jie Liu \\ School of Foreign Languages, Nanchang Normal University, Nanchang, China
}

\begin{abstract}
Critical thinking is one of the key skills for English majors, while the "critical thinking deficiency" is a commonplace among English majors in our country. The reasons for the "Critical Thinking Deficiency" of English major students lie in the ambiguous learning objects, the misleading guidance of teaching methods and the narrow knowledge, etc. It is effective to combine the development of critical thinking in the English writing process to improve the "critical thinking deficiency" among English major students. The paper aims to explore the development of the critical thinking ability in the English writing course by setting the real writing task, adopting the multi-draft writing, and establishing the students' writing portfolio, and in these ways the analyzing abilities, critical thinking abilities and the abilities to solve problems can be fostered, thus the students' writing abilities can be improved. .
\end{abstract}

Index Terms - Critical Thinking, English Writing, Critical Thinking Deficiency, theoretical model

\section{INTRODUCTION AND LITERATURE REVIEW}

As one of the most necessary aspects human lives, thinking, especially critical thinking, is needed in solving the problems in the difficult cases. The purpose of education system is to educate people to be independent and to think effectively. Students must be educated and motivated to research. They should not follow others without any investigation. (Kadivar, 2002) Critical thinking can help people form a critical conception of the society problems, rather than undisputed imitation. Recently, critical thinking has been a hot spot of research among English learning researchers, for the growing students' mental skills has always been an issue. However, the current state of Chinese English learners is that the phenomenon of "Critical Thinking deficiency" is still common among English majors. To the English majors students, "Critical Thinking deficiency" (YuanShen HUANG, 1998) arises due to students' lack of abilities of analysis, judgment, inference, reasoning and differentiation. The reasons for the "Critical Thinking Deficiency" of English major students lie in the ambiguous learning objects, the misleading guidance of teaching methods and the narrow knowledge, etc. In recent English writing teaching, much attention has still been paid to the language itself in teaching methods, and there is still a common phenomenon that English teachers lay much importance on the practice of language rather than the cultivation of thinking ability. As for students, much importance has been attached to the recitation and imitation instead of the analysis and the reflection of the problems. Summative assessment has prevailed in the assessment of English writing teaching.

Although many researchers have realized the importance and seriousness of the problem, no effective ways have been adopted to improve the critical thinking deficiency among English major students, especially in English writing teaching. It was mentioned in "English syllabus for English majors in Higher education" (2000) released by Higher Institution Foreign Language Teaching and Learning Advisory Committee that students of English majors shall be cultivated on the abilities to acquire knowledge, to think independently and to innovate. As the syllabus put it, having a command of English knowledge and ability to think critically is necessary especially for English majors. Therefore, more and more English experts have realized that "Critical thinking deficiency" shall be overcome in order to improve the critical thinking abilities among English majors.

Foreign scholars' research on critical thinking mainly includes the definition of critical thinking model and the construction of measuring tools. Researchers (Scriven \& aul,1987; John Dewey,1993; The Delphi Group, 90; cione, 990; Yeh, 2001; Geertsen, 2003; Salmon, 1989; Paul \& Elder, 2006) have already explored the definition and the connotation of critical thinking ability and have gain much achievements. However, the researches of critical thinking abilities at home are comparatively limited (Chongde Lin, 2006; Qiufang Wen, 2006, 2009; Qixin He, 1999). Yuanshen HUANG (1998) pointed out that the "Critical thinking deficiency" was common among English majors and analyzed the reasons. Wen (2009) compared the current situation of Critical thinking between English majors and other Liberal arts majors. Therefore, researches at home focus mainly on the reasons for critical thinking deficiency among English majors and some comprehensive strategies have been put forward. The researches of improving critical thinking ability in the specific courses, especially the English writing course, are limited. Thus the exploration of cultivation of critical thinking ability in English writing teaching is of great significance, for it is one of the most effective courses to develop

\footnotetext{
* Sponsored by funding of the program: English Teaching and Research Innovation Team project and the Project of On Cultivation of Readers' Awareness in English Writing from the Pragmatic Perspective (Social Science Planned Research Project of Jiangxi Province in 2017, 17YY14).
} 
the critical thinking abilities and one of the most effective way to improve "critical thinking deficiency". This paper aims to explore how to improve the critical thinking abilities effectively on the basis of the theoretical model of critical thinking.

\section{The TheORETICAL Model OF CRITICAL THINKING}

Currently the most influential theoretical models of critical thinking both abroad and at home include: the two-dimensional structure model proposed by the Delphi Research Group (1990); the Ternary structure model by Paul and Elder of Foundation for Critical Thinking (2006)and the three-edged structure by Chongde LIN (2006). The Delphi Research Group (1900) defined the critical thinking model from cognitive dimension and affective dimension. Paul and Elder (2006) defined the critical thinking model from three dimensions: the thought element, the measure standard and the intelligence characteristic. In order to measure the critical thinking ability of college students, The Delphi Group had designed two measures tools, namely California speculative skills scale and California Speculative Questionnaire, which received the reliability and validity tests for 4 years. Based on the foreign Critical ability model, Chongde LIN (2006) put forward the three-edged structure of critical thinking, which include six elements: thinking purpose, thinking process, thinking content self-monitoring in thinking, thinking quality, the cognitive and non-cognitive factors in the thinking.

But the most available and widely-adopted one at home is the hierarchy theory model of critical thinking proposed by Qiufang WEN (2009). This model combined the previous three models together, and its hierarchy theory model is easy to be operated and conducted in the teaching process. In this model, critical thinking falls into two levels: meta-thinking and thinking ability. Meta-thinking, as the first level, refer to the ability to plan, check, adjust and assess one's own thinking. The thinking ability of the second level include the cognitive skills (analytical ability, reasoning ability, and evaluating ability), standard (clarity, relevancy, logic, profundity, and flexibility) and emotional traits (curiosity, open, confidence, just and Integrity and perseverance). These two levels lie in the above-down layer, and the second level is managed and monitored by the first level. (Qiufang WEN,2009) (See chart one)

TABLE ONE:

THE THEORETICAL MODEL OF CRITICAL THINKING (QIUfANG WEN, 2009)

\begin{tabular}{|c|c|c|}
\hline \multicolumn{3}{|c|}{ Meta-thinking ability (self-regulation ability) } \\
\hline \multicolumn{3}{|c|}{ Thinking Abilities } \\
\hline \multicolumn{2}{|l|}{ Cognitive } & Emotional traits \\
\hline skills & Standard & Curiosity (inquisitive,curious, Studious ) \\
\hline $\begin{array}{l}\text { Analytical ability (Classification, } \\
\text { identification, comparison, clarification, } \\
\text { differentiation, interpretation) } \\
\text { Reasoning ability (Question, } \\
\text { hypothesis, inference, exposition, } \\
\text { argument, etc) } \\
\text { Evaluating ability (Evaluation } \\
\text { presupposition, assumption, argument, } \\
\text { argument, conclusion, etc) }\end{array}$ & $\begin{array}{l}\text { Clarity( Clear and accurate) } \\
\text { Relevancy(relevant, unified) } \\
\text { Logicality (coherent ) } \\
\text { Profundity(Logical, to be of } \\
\text { breadth, depth and difficulty) } \\
\text { Flexibility( Rapid change of } \\
\text { perspective, adept at alternating } \\
\text { using different thinking skills.) }\end{array}$ & $\begin{array}{l}\text { Open (Tolerate and respect different } \\
\text { opinions and be willing to correct their } \\
\text { own improper views.) } \\
\text { Confidence (Believe in your own } \\
\text { judgment and dare to challenge authority.) } \\
\text { Just and Integrity (Pursue truth and stand } \\
\text { for justice. ) } \\
\text { Perseverance(With determination, } \\
\text { perseverance, and don't give up easily.) }\end{array}$ \\
\hline
\end{tabular}

From what have been mentioned, the features of Wen's hierarchy theory model are obvious: first, the hierarchy is obvious and the focus is prominent. Meta-cognition plays the role of self-regulating, which occupies the highest position and plays a dominant role in the overall situation. By constantly planning, checking, adjusting and evaluating the ability of thinking, the subjective initiative and the leading role of the thinker are brought into full play. Second, the core of thinking ability is evaluation. With certain standards, we can make an honest and clear assessment of our thinking. Evaluation requirements are conducted in different ways, and the result of the evaluation is not either/or, but it should be diversified. Third, the ability to think is expressed through emotional characteristics. People who are curious, open, confident, honest and firm are usually strong thinkers. Therefore, cultivating these characters is the ultimate goal of cultivating critical thinking ability. Fourth, the ability to think can be cultivated and trained. We can learn a certain degree of self-control by taking classes and training, and then we can train the skills and emotional characteristics, and finally master the cognitive skills and the emotional characteristics.

\section{The Teaching OBJective OF CRITICAL Thinking IN ENGLish Writing}

"English writing" is a course that combines reading, argument and debate, and it's one of the effective way to develop critical thinking abilities of college students. Integrating the development of critical thinking into English writing is beneficial to the development of students' solving problems dialectically, and in verse, the development of critical thinking can effectively improve English writing abilities, thus broadening students' thinking and detailing the content.

In the English writing course, seven stages are involved in composing the argumentation: conception, orientation, deciding on the significance, generation of ideas, organization, feedback and revision. Students can draw happiness from the cooperating study with peers, gain confidence in the course of group discussion, learn to organize and express 
their own opinion by using the language strategies to cater to the demands of the potential readers and treat the problems dialectically, thus improving their critical thinking abilities.

In order to integrate the critical thinking abilities into English writing course, we set the teaching objects of English writing on the basis of the Wen's theoretical model.

For the meta-thinking, the first level, teachers shall cultivate the meta-thinking abilities in the pre-writing phase, in which brainstorming, mind mapping and group discussion are the effective ways. Teachers shall assign an open topic, and students can judge and choose their own key point of topic on the basis of their own interests and information reserve. During the course of brainstorming, mind mapping and group discussion, students' meta-thinking abilities (self-planning, self-adjustment, etc) are practiced and improved gradually, and they have to learn to evaluate their own information reserve, thoughtfully analyze and evaluate the alternative points of view, select and sort out the effective information and prepare for the further writing.

For cognitive abilities, the second level, students' analytic abilities, reasoning abilities and evaluation abilities can be greatly improved in the writing course. In self-evaluating and peers-evaluating process, students shall learn to analyze and evaluate their own composition and their peers'. They shall learn to find out the thesis statement, judge the effectiveness of the thesis statement and the logic of the organization, etc. Students can express clearly their own opinion and coherently and accurately interpret the pros and cons of the writing. As for the cognitive standards, they are the standards to inspect final products and evaluate the students' critical thinking abilities. For this part, students can assess the peers writing as well as their own writing on the view of reader identity. Clarity refers to the exactness of the thesis statement; relevancy concerns the relevance of thesis statement to the subject and the supporting sentences to the thesis statement. Students can judge the logic organization and the coherence of the sentences in the paragraph in the aspect of logic. Profundity concerns the depth and width of the argument and flexibility focuses on the different angles of argument.

Here comes the emotional traits of thinking; students have to look up the reference, choose the key topic, construct the effective thesis statement, thus curiosity of the social hot spot and the habit of collecting and reserving information can be improved and formed. Group discussion can effectively improve the cooperative study. Being open means students shall admit the existence of different opinion and accept the positive and negative evaluations from their peers, thus developing the open attitude in writing course. Students shall be confident to express their own idea and challenge the authorities in the group discussion and peers evaluation. Students shall learn to tell the truth in front of different information. Since the writing course requires at least three drafts of writing and the repeated revisions, perseverance are fostered greatly among students.

TABLE TWO:

THE TEACHING OBJECTS OF CRITICAL THINKING IN ENGLISH WRITING COURSE

\begin{tabular}{|c|c|c|}
\hline \multicolumn{2}{|c|}{ Meta-thinking(self-planning, self-adjustment) } & Thinking Abilities \\
\hline Cognitive & & Emotional traits \\
\hline skills & Standard & Curiosity (learners can determine the \\
\hline $\begin{array}{l}\text { Analytical ability (analyze the readers } \\
\text { before writing; establish the purpose of } \\
\text { writing;analyze the thesis; organize the } \\
\text { introduction, body paragraphs and } \\
\text { conclusion) } \\
\text { Reasoning ability (draft the effective } \\
\text { thesis statement) } \\
\text { Evaluating ability (distinguish the } \\
\text { facts and opinion; judge the convincing } \\
\text { of the evidence and logic in the } \\
\text { argument) }\end{array}$ & $\begin{array}{l}\text { Clarity( Whether the thesis is clear? } \\
\text { Is it understandable to readers?) } \\
\text { Relevancy(whether the thesis } \\
\text { statement is relevant) } \\
\text { Logicality (whether the content is } \\
\text { coherent) } \\
\text { Profundity (whether the argument is } \\
\text { profound and broad) } \\
\text { Flexibility( whether it is to argue the } \\
\text { thesis from the different views) }\end{array}$ & $\begin{array}{l}\text { topic via looking up the reference and are } \\
\text { willing to put forward the questions) } \\
\text { Open (learners can accept the peers' } \\
\text { positive and negative feedback) } \\
\text { Confidence (learners can positively } \\
\text { express ideas in the group discussion and } \\
\text { challenge the authorities) } \\
\text { Just and Integrity (learners can tell the } \\
\text { rights in front of the different topics) } \\
\text { Perseverance (learners can persist in the } \\
\text { whole writing course) }\end{array}$ \\
\hline
\end{tabular}

\section{The DeVelopment of CRITICAL Thinking AbILITIES In ENGLiSh Writing}

In view of the significance of cultivation of critical thinking in English writing, this paper aims to explore the effective ways to improve the critical thinking by combining the development of language acquisition, language skills and critical thinking together. Given the teaching objectives of critical thinking in English Writing course, setting the real writing task, adopting the multi-draft writing, and establishing students' writing portfolio in our own teaching experience are widely used to improve the critical thinking in English writing course.

\section{A. Setting the Real Writing Task to Stimulate Students' Critical Thinking}

In English writing course, setting the real writing task is the premise to cultivating students' writing ability. Teachers in assigning the writing tasks should focus on helping students solve the problems in real lives or the themes related to students' daily life, guiding students to analyze the causes of the problem and thus solving the problem. As for these writing tasks related to students' daily life, students tend to "have words to say", and it is easy to stimulate the students' information reserves, put forward and demonstrate their own point of view, so as to cultivate students' independent thinking.In this way, students will be more willing to participate in writing activities. At the same time, students' fear of 
difficulties can effectively avoided in some way, and it can help students' value perception, reflection and understanding ability. It must be ensured that students have plenty of time to think, and practice the students' thinking ability. The following topics are always designed in the teaching experiences: "idol worship", "Your Opinion on Campus Loan?", "The advantages and disadvantages of micro-blog", "The effects of artificial technology on our lives", "The sharing bicycles" and so on. These topics concerns student's own lives and experiences, and the students are greatly motivated, and get access to the point of view easily, thus the contents of the article are comparatively full and rich, and argument is sufficient and persuasive. It can greatly improve the students' interest in writing and make them "have words to say," enabling students to construct actively their own knowledge system, to overcome the fear of difficulties, and to help students focus on conception, reflection and comprehension, thus cultivating the ability to analyze problems and thinking.

When the assignment is set, teachers shall use brainstorming or mind mapping to help students generate ideas from their information reserve. Mind mapping can guide students to point out the key words of the topic. Exploratory teaching methods are usually adopted in the process to develop students' analytic and thinking ability and competence of solving problems.

Besides, our teaching experiences showed that "given-material composition" can be adopted in the English writing class to combine the training of language skills and development of thinking ability. In "given-material composition", students have to read a reading material and then finish the assignment designed from the material. The assignment can be topic composition, semi-topic composition or open composition. Some evidences include the pros and cons are listed in the material, so students need to examine the materials thoroughly in order to decide their own point of view. They have to analyze and reason the information in the reading material, and at the same time, they learn the idiomatic expressions through reading materials. Via these activities, students' language and thinking abilities can be trained and improved simultaneously.

\section{B. Adopting Multi-draft Writing and Multi-feedback to Improve Students "Readers" Awareness}

In our teaching experience, writing course concerns several phases, and the each composition shall be revised for at least three times to reach the final product. Getting the first draft peer-reviewed is very important. Reading the peers writing is an effective way to see your peers works and your own critically from the view of readers, thus improving the students' readers awareness and the ability to read the works dialectically. Peers review can train students in reading, writing and communicating, and students can learn to accurately interpret their own opinion.

In this course, writing "workplace" is always adopted in the process. Before the class, the workplace of three to four peers can be formed according to students' performance, personalities, gender and their own will. The group members shall put forward their learning regulation, making sure their individual role and function, thus achieving in the collaborative learning. In the learning process, the workplace will receive an assignment, and the whole group will cooperate together to finish the seven phases of writing process.

Collaborative work is typical in the real group workplace. Students can make use of the chance to gain experience in collaborative work. Peers-feedback is a component part of process English writing, and it can cultivate students "readers" awareness. It can help students learn to view the workers from the point of readers, and as an independent reader, a student can read his own works critically. Questions excerpted from "A Handbook of Writing" (The third Edition) by Wangdao DING (2009) are often used in peers feedback:

1. What is the topic of the essay / composition? Does the draft fulfill the assignment (e.g. mode of development or type of composition)? Is the thesis clear? Is it supported by enough facts (details, examples, reasons, etc.)?

2. Is there irrelevant material that should be removed? Is the logic sound? Are there gaps in the logic?

3. Is each sentence clearly related to the sentence that precedes it and to the sentence that follows? Are there unnecessary sentences that may be removed? Are there structural mistakes? Are there wordy and redundant sentences? Is there variety in sentence type?

4. Are there words that are not appropriate for the topic or the style of the whole essay (e.g. too colloquial or too formal)?Are there words or phrases which are directly translated from Chinese but which may mean something different in English? Are there collocations which may be incorrect because they are taken from Chinese (e.g. a big rain)? (Wangdao DING, 2009)

Multi-feedback is often adopted in the process of writing. There are self-feedback, peers-feedback, teacher-student feedback, oral feedback, face-to-face feedback, and written feedback. All these kinds of feed-backs are sometimes overlapping, and exist in different phases of writing(See chart three). Multi-feedback can improve students critical thinking, because students can objectively view their and peers' works, improving their analytic abilities. Of the same age, students are always trust-able mutually and frank to each other, and they will point out the pros and cons at the presence of each other, put forward their own opinions, discuss heatedly if it is possible and reach a consensus of the final revision. Traditional "teachers-revision-oriented" model has been shifted into "students-and -process-oriented" model. In this way, students always dare to "say"something because they have more confidence in fronts of their peers. They can experience, reflect mutually, collaborate, communicate with each other and their learning interests and curiosity can be greatly stimulated. With the mutual communication, students can spark the writing and cultivate the critical thinking abilities. 
TABLE THREE:

MULTI-FEEDBACK IN THE WRITING PROCESS

\begin{tabular}{|l|l|l|l|l|}
\hline & Brainstorming & First draft & Second draft & Product draft \\
\hline Self-feedback & & $\sqrt{ }$ & $\sqrt{ }$ & $\sqrt{ }$ \\
\hline Teacher-student feedback & & & $\sqrt{ }$ & $\sqrt{ }$ \\
\hline Peers feedback & $\sqrt{ }$ & $\sqrt{ }$ & & \\
\hline Oral feedback & $\sqrt{ }$ & $\sqrt{ }$ & $\sqrt{ }$ & \\
\hline Face-to-face feedback & $\sqrt{ }$ & & & \\
\hline Written feedback & & & & $\sqrt{ }$ \\
\hline
\end{tabular}

\section{Establishing Students' Writing Portfolio to Develop Students'Reflective and Analytic Abilities}

Students' writing portfolio are the exercise books which record the whole course of students writing, including the pre-writing phase (brainstorming and group discussion), in-writing phase (the first draft, the peers feedback and self-feedback), and the post-writing phase (the second draft, teacher-student feedback and third draft). The whole writing course will be recorded to present students' performance of different phases, and students can recall and reflect ceaselessly their own works and review them on the basis of peers and teachers' feedback from the prospects of conception , organization, tone, logic and the coherence of the discourse planning, thus improving their critical thinking abilities.

With the portfolio, the evaluation of the students' writing shall be shifted accordingly. Formative evaluations are adopted in this way. Students' writing portfolio makes the formative evaluations possible, including students' participating in the group discussion in the class (30\%), the performance of daily assignments (50\%) and the outcome of the final examinations (20\%). Among those elements, the performance of daily assignments for most part reflect students' true writing levels, for in the portfolio, students' whole writing process can be recorded.

In order to gain better effects of the portfolio, more instructors are always needed in the course of teachers' feedback. In our action research, we found that due to the time limitation and reliability of students on teachers, more instructors are needed at the first period of training. Teachers shall train students to view and revise the composition and encourage students to challenge the authority, thus forming the habit of revising the composition from the view of readers. Only in these ways can portfolio be maximally taken advantage of and students' critical thinking abilities can be simultaneously improved.

\section{CONCLUSION}

Combining the cultivation of critical thinking into the whole course of writing is of great importance in cultivating students' critical thinking abilities. In the pre-writing phase, brainstorming and mind mapping can effectively cultivate the students' critical thinking model; self-revision, peers-revision and the teacher's revision in the post-writing phase can help students view their own and peers' works from the view of readers, thus spotting the problem, solving the problems and enhancing the readers awareness. During the whole course, analytic abilities, critical thinking abilities and competence of solving problems can be greatly improved. Students shall learn to monitor their own writing process, reflect and analyze, cultivating the critical thinking abilities with the improvement of writing levels.

The above-mentioned are the rough suggestions drawn from our teaching experiences. It is well-known that the cultivation of critical thinking ability is a long process, which cannot be achieved overnight. Thus, to the English writing teachers, the awareness of critical thinking abilities shall be clung to in the designing the teaching process. Those targeted training enables students to acquire the cognitive skills of meta-cognitive strategy and critical thinking ability, and have the emotional characteristics of thinking ability, thus improving their thinking quality.

\section{REFERENCES}

[1] American Philosophical Association. (1990). The Delphi Report Executive Summary: Research Findings and Recommendations Prepared for the Committee on Pre-college Philosophy. ERIC Doc No Ed 35423.

[2] Brown, H. D. (2001). Teaching by principles: An Interactive Approach to Language Pedagogy (2nd ed.) White Plains: Addison Wesley Longman, Inc.

[3] Chongde LIN. (2006). Reflections on the Researches of Thinking Psychology. Journal of Beijing Normal University, 5, 35-42.

[4] Facione, P.A. (1990). Critical Thinking: A Statement of Expert Consensus for Purposes of Educational Assessment and Instruction. California: The California Academic Press.

[5] Foreign Language Teaching in Colleges and Universities Steering Committee. (2000). English Syllabus for English Majors in Higher Education. Beijing: Foreign Language Teaching and Research Press.

[6] Hyland, F. (1998). The Impact of Teacher Written Feedbacks on Individual Writers. Journal of Second Language Writing, 7 , 255-286.

[7] Kadivar, P. (2002). Educational psychology. Tehran: Samt.

[8] Nunan, D. (1991). Language Teaching Methodology: A Textbook for Teachers. London : Prentice Hall International (UK) Ltd.

[9] Paul, R. (1995). Critical Thinking: How to Prepare Students for a Rapidly Changing World. Santa Rosa, CA: Foundation for Critical Thinking.

[10] Paul, R.W., \& Elder, L. (2002).Critical thinking: Tools for taking charge of your professional and personal life. Upper Saddle River, NJ: Pearson Education, Inc. 
[11] Paul, R.W., \& Elder, L. (2006). Critical Thinking: Learn the Tools the Best Thinkers Use. New Jersey: Pearson Prentice Hall.

[12] Qiufang WEN. (2009).To construct the theoretical framework of Chinese foreign language college students' thinking ability. Foreign Language World, 1,37-43.

[13] Qixin HE. (1999). On Reform of the Foreign Language Professional Undergraduate Education. Foreign Language Teaching and Research, 1, 24-28.

[14] Yuanshen HUANG. (1998). Critical Thinking Deficiency. Foreign Languages and their teaching, 7, 1-19.

Jie Liu was born in Jiangxi, China in 1978. She is currently an associate professor in Nanchang Normal University. Her research interests include Applied Linguistics and second language pedagogy. Professor Liu has hosted and finished almost 10 research projects at provincial level, published over 30 academic papers on English language teaching and a set of textbooks. 